\title{
ALÉM DA PRIMEIRA VISTA: PROPOSTAS METODOLÓGICAS PARA A ANÁLISE FOTOGRÁFICA NO CONTEXTO COLONIAL MOÇAMBICANO
}

Leandro Antonio Guirro

Universidade Estadual Paulista - UNESP, Curso de História, Assis, SP. E-mail: leandro guirro@hotmail.com. Agência de fomento: CNPq

\section{RESUMO}

As fontes ainda são obstáculos para estudiosos que se interessam pela história da África. Deste modo, o trabalho que segue tem como principal finalidade contribuir com o desenvolvimento de alternativas que viabilizem pesquisas sobre o continente africano. Para tal, vale-se de propostas metodológicas (elaboradas por Kossoy, Benjamim, Burke, Meneses, Mauad e Paiva) que permitam compreender os Álbuns Fotográficos e Descritivos da Colônia de Moçambique, produzidos por colonos portugueses no final da década de 1920. Aponta-se que o ato fotográfico é composto por vários elementos, significados e intencionalidades que devem ser questionados por quem analisa as imagens. Conclui-se que as interpretações expostas compõem relevante subsídio para o estudo de documentos fotográficos, ligados ou não à temática africana.

Palavras-chave: Fotografia. Método. Moçambique. Colonização.

\section{BEYOND THE FIRST SIGHT: METHODOLOGICAL PROPOSALS FOR THE PHOTOGRAPHIC ANALYSIS IN MOZAMBIQUE'S COLONIAL CONTEXT}

\begin{abstract}
The sources are still obstacles to researchers interested in the history of Africa. Thus, the work that follows its main purpose contributing to the development of alternatives that facilitate research about the African continent. For this purpose, it is methodological proposals (developed by Kossoy, Benjamin Burke, Meneses, Mauad and Paiva) that allow understand the Photo Albums and Descriptions of the Colony of Mozambique, produced by Portuguese colonists in the late 1920s. It pointes that the photographic act consists of several elements, meanings and intentions that should be questioned by those who analyze the images. It concludes that the exposed interpretations make relevant data for the study of photographic documents, linked or not with African theme.
\end{abstract}

Keywords: Photography. Method. Mozambique. Colonization. 


\section{INTRODUÇÃO}

As fotografias fazem parte do cotidiano das pessoas. Elas deixam registrados os mais variados acontecimentos vivenciados por cada um. Momentos íntimos, festas, cerimônias, viagens, e até funerais, podem ser transformados em imagens "eternas", captadas pelos cliques dos muitos tipos de câmera que existem. O acelerado desenvolvimento tecnológico contribui para a rápida produção de imagens em celulares e demais equipamentos digitais, bem como para a difusão das obras em programas de televisão, jornais, sites, redes sociais, dentre outros meios afins. Pode-se dizer que atualmente tudo e todos são passíveis de serem fotografados por profissionais ou amadores.

Deste modo, cabe a seguinte indagação: como os historiadores devem lidar com a fotografia enquanto documento histórico? As linhas que seguem têm a singela intenção de levantar problemáticas e discussões traçadas por estudiosos que debatem o assunto, utilizando-se dos Álbuns Fotográficos e Descritivos da Colônia de Moçambique, produzidos por colonos portugueses durante a década de 1920.

\section{METODOLOGIA}

Benjamim (1994, p.91) mostrou-se muito salutar ao afirmar, no início do século $X X$, que "a névoa que recobre os primórdios da fotografia é menos espessa que a que obscurece as origens da imprensa". E foi exatamente sua "Pequena História da fotografia" que colaborou para que a "névoa" que encobria a fotografia começasse a se dissipar. Refletindo sobre a tensão criada entre a pintura e o surgimento da fotografia, o autor lançou balizes para interpretações e questionamentos dos registros captados pelas lentes das máquinas na mesma época em que os Álbuns Fotográficos e Descritivos da Colônia de Moçambique foram elaborados. Ou seja, a leitura dessa obra proporciona, além de ponderações a respeito das imagens em si, considerações fundamentais sobre o ato fotográfico como um todo.

A produção, por exemplo, é um ponto de destaque na perspectiva do filósofo alemão. De acordo com suas palavras, "o decisivo na fotografia continua sendo a relação entre o fotógrafo e sua técnica" (BENJAMIM, 1994, p.100). Deste modo, interessa questionar não apenas o que foi registrado em determinado momento, mas a forma como este processo se desencadeou sob a ação de um ser humano. Os aspectos práticos, como tipo de aparelho utilizado, iluminação, tomada, etc., interferem diretamente no resultado final do trabalho e ampliam o leque de interpelações sobre a obra e o próprio autor. 
Kossoy (2001, p.84) segue a mesma linha de raciocínio, destacando que o entendimento a respeito da tecnologia empregada permite aproximação maior com o período em que a foto foi produzida. Assim, torna-se fundamental a capacidade de reconhecimento dos processos de produção fotográfica empregados ao longo da história. Todavia, mesmo que importante, a produção é apenas parte do caminho. Igual relevância deve ser creditada à recepção, ou seja, a forma como a fotografia pode ter tocado o observador, quais as possíveis leituras que os sujeitos podem ter realizado em determinado momento histórico (KOSSOY, 2000, p.42).

Ana Maria Mauad define a situação comentada acima como uma relação entre autor, texto (visual) e leitor. Nas considerações da autora, além dos sujeitos envolvidos no ato fotográfico, o contexto histórico-social no qual a atividade se desenvolve é fator preponderante. Outros pesquisadores comungam da mesma opinião e tratam o tema com muito cuidado. Kossoy (2007, p.52), por exemplo, aponta que o "fragmento fotográfico adquire significado quando se percebem as múltiplas teias que o enlaçam ao contexto histórico e à vida social em que se insere e, ao mesmo tempo, documenta". Já Lima e Carvalho (2012, p.35) enaltecem que o contexto da imagem não diz respeito a seu conteúdo propriamente dito, mas aos modos de apropriação reservados à fotografia. Deste modo, fatores como produção, circulação, consumo, descarte e institucionalização transformam-se em elementos fundamentais para a análise histórica acerca da fotografia. Somando-se aos demais itens, Kossoy (2001, p.45) lembra ainda que o quesito "intenção" do fotógrafo também deve ser pensado como ponto de investigação.

Entretanto, o cerne da questão, na visão de Bezerra de Meneses, é discutir o conceito de "História Visual". Segundo o autor, os documentos fotográficos não devem ser necessariamente os objetos de pesquisa do historiador. Pelo contrário, eles devem ser entendidos como instrumentos que podem viabilizar interrogações sobre a sociedade. Destarte, as fotografias são o caminho e não o fim da linha.

Assim, a expressão "História
visual" só teria algum sentido
se se tratasse não de uma
História produzida a partir de
documentos
(exclusivamenter ou
predominantemente), mas de
qualquer tipo de documento e
objetivando examinar a
dimensão visual da sociedade
(MENESES, 2003, p.23).

As orientações destes estudiosos deixam claro, portanto, que as fotografias carregam consigo uma gama de informações intrínsecas que necessitam de averiguação e aprofundamento. O alerta Paiva (2002, p.11) não poderia ser mais claro: "é importante 
sublinhar que a imagem não se esgota em si mesma. Isto é, há sempre muito mais a ser apreendido, além daquilo que é nela dado a ler ou a ver".

\section{RESULTADOS}

Os pressupostos apontados até 0 momento mostram-se enriquecedores para alargar os questionamentos referentes ao material fotográfico discutido. Os registros fotográficos foram produzidos em 1929 e divididos em 10 álbuns que mostram o cotidiano de Lourenço Marques (capital) e dos distritos de Gaza, Inhambane, Quelimane, Tete e Cabo Delgado. O último volume da coleção trata especificamente dos usos e costumes praticados pelos chamados indígenas. De modo geral, as imagens captam as relações cotidianas das pessoas em espaço público, enaltecem a infraestrutura das cidades, apontam o sucesso de atividades econômicas e formulam uma sensação de bem estar e progresso.

De acordo com Silva (2013, p.10), o conjunto de fotografias reflete o olhar colonizador de seu editor, José dos Santos Rufino, e o de seus colaboradores, tenente Mário Costa (autor dos textos introdutórios) e padre Vicente do Sacramento, sobre o caminho que os indígenas deveriam percorrer até alcançarem a cidadania. As discussões metodológicas apontadas pelos pesquisadores comentados permitem que esta hipótese seja tratada com maior propriedade e que também sejam elaboradas outras conjecturas baseadas em indagações mais aprofundadas sobre a autoria, produção, circulação e intencionalidade envoltas na realização do referido empreendimento.

O próprio formato no qual as imagens são apresentadas é digno de atenção especial. Segundo Lima e Carvalho (2012, p.94), os álbuns fotográficos de cidades remontam a meados do século XIX e conseguiram conquistar rápida aceitação popular. Ao representar vários aspectos das cidades, compõem "um tipo de publicação no qual a imagem é predominante e assume um papel ativo na construção de sentidos, articulando-se, ao invés de submeter-se aos textos e legendas".

Contudo, mesmo que não sejam prevalecentes, as legendas criadas para cada fotografia também são relevantes. Elas podem conter tanto informações que contribuem para o entendimento do que foi registrado, quanto indícios sobre o imaginário do fotógrafo e da própria sociedade acerca do objeto, pessoa ou paisagem eternizada pela câmera. Fotografia e legenda formam um todo indissociável, parte de um mesmo corpo. Os textos que acompanham as fotografias podem ajudar na compreensão das mesmas ao marcar dados explicativos, como local, data, identificação 
dos fotografados, nome do fotógrafo, dentre outros. Porém, eles ainda podem conter informações mais profundas. Vejamos o caso da imagem seguinte:

Figura 1. Áshiça - o galêgo africano. Condutor de "Ricshaw" com os ornamentos esquisitos usados por "colegas" estrangeiros, mas que a Polícia de Lourenço Marques não parece disposta a permitir...fora da época carnavalesca.

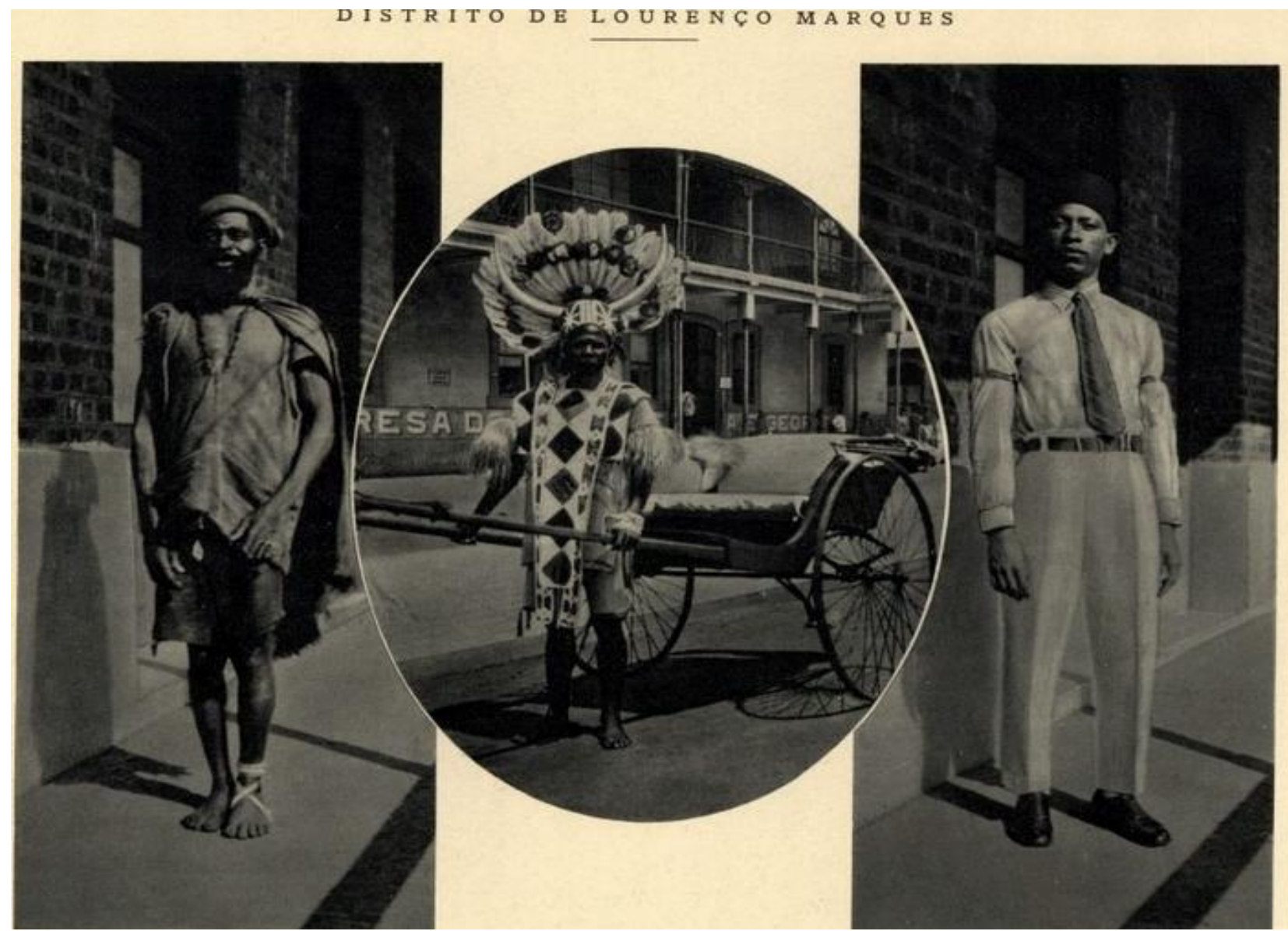

É evidente que a legenda traz informações sobre as personagens retratadas na capital da colônia portuguesa em Moçambique no ano de 1929. Todavia, ela conjuntamente carrega consigo o juízo de pretensa superioridade do europeu, ao referir-se de forma jocosa aos trajes "esquisitos" usados pelos africanos, indicados somente para a época de carnaval. Considerar as legendas mais que meros apêndices informativos ajuda na construção de análises mais abrangentes e enriquecedoras das obras fotográficas.

\section{DISCUSSÃO}

Ao analisarem fotografias, os historiadores precisam se atentar para o inconsciente, o não proposital que insiste em deixar sua marca. Segundo Benjamim,

A natureza que fala à câmara não é a mesma que fala ao 
olhar, é outra, especialmente porque substitui a um espaço que ele percorre inconscientemente.

Percebemos, em geral, o movimento de um homem que caminha, ainda que em grandes traços, mas nada percebemos de sua atitude na exata fração de segundo em que ele dá um passo. A fotografia nos mostra essa atitude, através de seus recursos auxiliares: câmara lenta, ampliação. Só a fotografia revela esse inconsciente ótico, como só a psicanálise revela o inconsciente pulsiona (BENJAMIM, 1994, p.100)I.

Nesta perspectiva, é creditado à fotografia o poder de revelar minúcias que olhares apressados não conseguem captar. Ao tornar estáticas as cenas e as personagens contempladas e oferecer recursos tecnológicos que conseguem viabilizar pontos de vistas aprofundados, a fotografia amplia os horizontes interpretativos e pode trazer à tona algo não previsto ou considerado no momento do clique.

Fotografia não é apenas técnica e estilo. É, também, percepão, sensibilidade e parcialidade. O que nela encontramos é uma "visão da sociedade num sentido ideológico, mas também visual (BURKE, 2004, p.49)". Para Sontag (1981, p.7), o fotógrafo impõe sua "visão de mundo" no momento em que decide como deverá ser uma fotografia, apresentando ali sua interpretação acerca do objeto ou evento contemplado.
Cabe ao pesquisador que trata a fotografia como fonte histórica aguçar sua percepção e atentar-se para os pormenores contidos no registro fotográfico. E para fazêlo, é preciso, tal qual disse Kossoy (2007, p.45), "desmontar" as fotografias e tentar descobrir aquilo que elas trazem nos planos interior e exterior. Afinal, compreender o que foi fotografado é tão complicado quanto analisar o roteiro de produção, circulação e recepção das imagens. É exatamente por isso que pesquisadores desenvolvem planos metodológicos específicos para trabalhar com as imagens.

Um dos que se dedicam a essa atividade é Ulpiano T. Bezerra de Meneses. Sua proposta se alicerça em três pilares básicos: o visual, o visível e a visão. $\mathrm{O}$ aspecto visual é aquele que engloba fatores que compõem os sistemas de comunicação visual e os ambientes visuais em si, tal qual produção, circulação, consumo, instituições, etc. Já o plano visível está relacionado "aos objetos de observação e às prescrições sociais e culturais de ostentação e invisibilidade". Por último, temos a visão, que diz respeito aos instrumentos e técnicas utilizadas pelo observador, seus modelos e formas de olhar (MENESES, 2002, p.31).

No entendimento de Lima e Carvalho (2012, p. 46), por outro lado, a análise fotográfica baseia-se em três "leituras": a primeira é a análise morfológica (atributos 
formais); a segunda diz respeito aos contextos de produção e circulação das fotgrafias; a última, "um grande desafio para os historiadores", concentra-se em avaliar o impacto social causado pelo uso das imagens estudadas.

Para Kossoy (2007, p.46), a decifração da fotografia deve pautar-se tanto pelo viés iconográfico, quanto pelo iconológico. A leitura iconográfica busca detectar os elementos constitutivos da imagem, como fotógrafo, tecnologia utilizada, assunto, tempo e espaço. Empregando a terminologia criada por Panofsky (1991, p.30), a interpretação iconológica volta-se "para a decifração daquilo que o fragmento visual não tem de explícito em seu conteúdo". Percebe-se, assim, que os registros fotográficos ganham dimensões ainda mais dinâmicas e enriquecedoras.

\section{CONCLUSÃO}

Mesmo que tenham sido apresentados de forma prévia, pode-se notar que as propostas metodológicas possuem muito mais similaridades do que discrepâncias. De modo geral, caminham numa mesma direção e conseguem sintetizar um ponto de partida importante para a compreensão do universo fotográfico. Estes e outros esquemas interpretativos representam um avanço significativo no aprimoramento do olhar histórico e historiográfico acerca das imagens.

Diante da vastidão dos debates em relação ao campo fotográfico, pode-se dizer que as observações feitas até o momento significam apenas os primeiros passos de um caminho longo e sinuoso. Ciente de que muitas das discussões levantadas aqui foram feitas de modo preliminar, é possível afirmar que o principal objetivo do texto apresentado foi esquematizar reflexões sobre o uso de fotografias enquanto fontes históricas. Porém, o benefício alcançado foi maior, tendo em vista que a execução desse exercício intelectual alargou os horizontes sobre a complexidade inerente ao ofício do historiador e suas ferramentas.

\section{REFERÊNCIAS}

BENJAMIM, W. Pequena História da Fotografia. In: Magia e técnica, arte e política: ensaios sobre literatura e história da cultura. São Paulo: Brasiliense, 1994, v.1.

BURKE, P. Testemunha ocular: história e imagem.. Bauru, SP: EDUSC, 2004.

KOSSOY, B. Fotografia \& História. 2.ed. São Paulo Ateliê Editorial, 2001.

Os tempos da fotografia: o efêmero e o perpétuo. Cotia: Ateliê Editorial, 2007.

Realidades e ficções na trama fotográfica. 2.ed. Cotia: Ateliê Editorial, 2000.

LIMA, S. F. de; CARVALHO, V. C. de. Fotografias: usos sociais e historiográficos. In: 
PINSKY, C. B.; LUCA, T. R. de. O Historiador e suas fontes. São Paulo: Contexto, 2012.

MAUAD, A. M.. Através da imagem: fotografia e história interfaces. Tempo, Rio de Janeiro, v.1, n.2, 1996.

MENESES, U. T. Bezerra de. "Fontes visuais, cultura visual. Balanço provisório, propostas cautelares". Revista Brasileira de História, São Paulo, v..23, n.45, , p. 11-36, 2003

PAIVA, E. F.. História \& Imagens. Belo Horizonte: Autêntica, 2002.

PANOFSKY, E. Iconografia e Iconologia: uma introdução ao estudo do Renascimento. In:__. Significado nas Artes Visuais. São Paulo: Perspectiva, 1991.

SILVA, A. C. F. N. da. Fotografando o mundo colonial africano Moçambique, 1929. Varia hist., Belo Horizonte , v. 25, n. 41, 2009. Disponível em: <http://www.scielo.br/scielo.php?script=sci_ arttext\&pid=S010487752009000100006\&lng =en\&nrm=iso >. Acesso em: 12 Sept. 2013.

SONTAG, Susan. Ensaios sobre fotografia. 2. ed. Rio de Janeiro: Arbor, 1981.

Recebido para publicação em 10/08/2015

Revisado em 27/08/2015

Aceito em 01/09/2015 